Dansk Ultralyddiagnostisk Selskab

\title{
Clinimetric properties of Strain Elastography in patients with supraspinatus tendinopathy
}

\author{
Karen Brage ${ }^{1,2}$ \\ ${ }^{1}$ Department of Sports Science and Clinical \\ Biomechanics, University of Southern \\ Denmark, Denmark \\ ${ }^{2}$ Health Sciences Research Centre, UCL \\ University College, Denmark
}

Strain Elastography (SEL) has previously shown potential for increasing diagnostic accuracy in Achilles tendon pathology and common flexor tendon pathology [1-3], and for predicting tendon damage in the Achilles tendon [4-6]. However, there is currently unclear clinimetric properties of SEL in terms of reliability, validity and responsiveness, for patients with supraspinatus tendinopathy.

The intra-rater and inter-rater reliability were tested using 35 healthy controls without shoulder pain and 35 patients suffering from clinical and MRI-verified supraspinatus tendinopathy.

Both quantitative SEL outcomes, including raw strain elastography index values (RAW), ratios with the reference areas placed in the deltoid muscle (DELT) and in a gel pad (GEL), as well qualitative variables, in the form of colour ratings as the number of soft lesions in the tendon, were reported. Acceptable intra-rater and inter-rater reliability were found using either of the SEL methods. However, the RAW variable had the highest reliability, and the measurement error from GEL exceeded the difference between healthy participants and patients [7].

The discriminative validity of SEL was tested between patients with clinical and MRIverified supraspinatus tendinopathy and healthy shoulder controls ( $\triangleright$ Fig. 1). In addi-
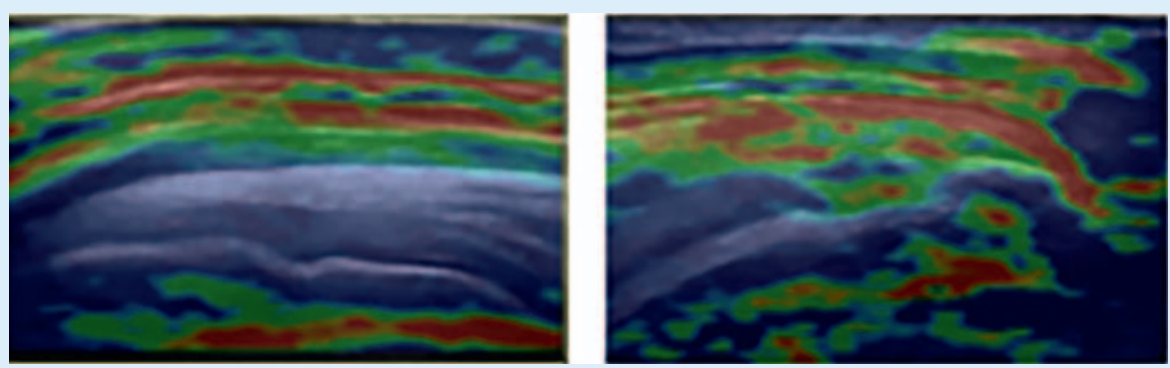

- Fig. 1 In the left image, an asymptomatic stiff (blue) supraspinatus tendon and in the right image a symptomatic softer (green, yellow, red) supraspinatus tendon is illustrated.

tion, the convergent validity was investigated in terms of associations between SEL and MRI, tendon thickness, and self-reported shoulder function (Disability of the Arm, Shoulder and Hand questionnaire (DASH)). SEL was reported as RAW, DELT, colour ratings and number of red/yellow lesions. Only RAW and DELT were able to discriminate significantly between patients with supraspinatus tendinopathy and healthy shoulder controls (adjusted for sex and BMI). Only RAW, MRI and DASH were statistically and significantly associated (adjusted for sex and BMI), meaning that patients with MRI-verified tendinopathy and/or increased disability had softer tendons [8].

The responsiveness of SEL (RAW and DELT) was investigated after 12 weeks of exercise treatment (symptomatic shoulder only) among 23 patients with unilateral clinical supraspinatus tendinopathy and compared with SEL from the same patients' asymptomatic supraspinatus tendon.

In addition, SEL was compared with changes in patient-reported outcome (DASH, pain ratings on a Visual Analogue Scale (VAS) and Global Perceived Effect (GPE), ultrasound tendon thickness and MRI) from the symptomatic tendon.
Responsiveness of SEL was not obtained after 12 weeks of shoulder exercising; however, most patients showed statistically significant improvement on patient-reported outcomes (pain and function) after the intervention. In addition, neither MRI (tendinopathy grading) nor ultrasound (tendon thickness) changed significantly (symptomatic tendon) after the intervention, but statistically significant correlations between increased tendon thickness and tendon softening were found [9].

\section{References}

[1] Klauser AS, Miyamoto H, Tamegger M et al. Achilles tendon assessed with sonoelastography: Histologic agreement. Radiology 2013; 267: 837-842

[2] Klauser AS, Pamminger M, Halpern EJ et al. Extensor tendinopathy of the elbow assessed with sonoelastography: histologic correlation. Eur Radiol 2017; 27: 3460-3466

[3] Klauser AS, Pamminger MJ, Halpern EJ et al. Sonoelastography of the Common Flexor Tendon of the Elbow with Histologic Agreement: A Cadaveric Study. Radiology 2017; 283: 486-491

[4] Balaban M, Idilman IS, Ipek A et al. Elastographic Findings of Achilles Tendons in Asymptomatic Professional Male Volleyball Players. Journal of ultrasound in medicine: official journal of the American Institute of Ultrasound in Medicine 2016; 35: 2623-2628 
[5] Ooi CC, Schneider ME, Malliaras P et al. Prevalence of morphological and mechanical stiffness alterations of mid Achilles tendons in asymptomatic marathon runners before and after a competition. Skeletal Radiol 2015; 44: 1119-1127

[6] Ooi CC, Schneider ME, Malliaras P et al. Sonoelastography of the Achilles Tendon: Prevalence and Prognostic Value among Asymptomatic Elite Australian Rules Football Players. Clinical Journal of Sport Medicine 2016; 26: 299-306

[7] Brage K, Hjarbaek J, Kjaer P et al. Ultrasonic strain elastography for detecting abnormalities in the supraspinatus tendon: an intra- and inter-rater reliability study. BMJ open 2019; 9: e027725

[8] Brage K, Hjarbaek J, Boyle E et al. Discriminative and convergent validity of strain elastography for detecting tendinopathy within the supraspinatus tendon: a cross-sectional study. JSES Int 2020; 4: 310-317

[9] Brage K, Juul-Kristensen B, Hjarbaek J. Strain elastography - follow-up after 12 weeks of rotator cuff exercises in patients with supraspinatus tendinopathy - a pilot study. OJSM [in press]

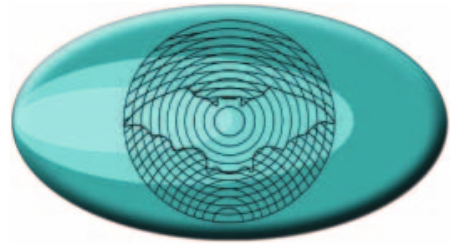

SAVE THE DATE - 23/4-2021

\section{DUDS årsmøde og generalforsamling}

med efterfølgende middag

\section{Rigshospitalet/CAMES}

Flot program med bl.a. videnskabelige indlæg, foredragskonkurrence og hands-on følger snarligt

i DUDS-blad på www.duds.dk 